\title{
Structural convergence among ASEAN economies
}

\begin{abstract}
A successful economic integration is meant to assist the backward member states to catch-up with the more advanced members in terms of development. As a result, the backward member states have their economy shifted from an agriculture-dominant economy towards industrial (with higher labour productivity) and then the service-dominant economy in order to maintain sustainability. With the catching-up in terms of the dominance of production, their economic structure shall become more similar with the more advanced members over time and hence experiencing structural convergence. Therefore, income convergence is expected when these backward member states have their income per capita increased alongside with the structural convergence. Evidences of income convergence within ASEAN are lacking and not much of the studies focused on the convergence in terms of the development stages within ASEAN. Since the dominance of production is always being used to refer to stage of development, therefore this paper would like to investigate on the production structure among ASEAN member states using the Krugman Index. Our results revealed an increasing structural convergence within ASEAN. The newer members of ASEAN namely Cambodia, Laos, Myanmar and Viet Nam (i.e., CLMV) had been catchingup with the more advanced members in their development. Though, the mining and utilities sector turned to be the sector that impedes further structural convergence for all. On the other hand, big share of agriculture sector among the CLMV countries become their main factor to slow down the structural convergence.
\end{abstract}

Keyword: ASEAN; Development gap; Production structures; Sector; Structural convergence 
